
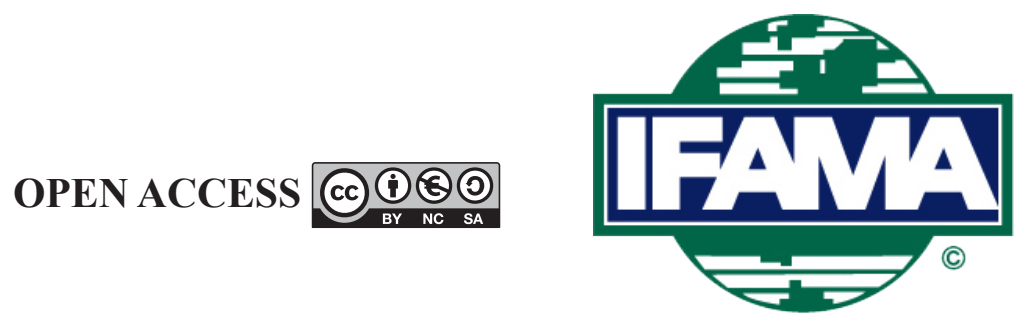

International Food and Agribusiness Management Review

Volume 24, Issue 3, 2021; DOI: 10.22434/IFAMR2020.0116

Received: 22 July 2020 / Accepted: 19 November 2020

\title{
Canadian dairy regulations as a driver of foreign direct investment: the case of Saputo
}

\section{RESEARCH ARTICLE}

\author{
James Rude ${ }^{\mathrm{a}}$ and Ellen Goddard ${ }^{\circledR b}$ \\ ${ }^{a}$ Associate Professor, ${ }^{b}$ Professor, Department of Resource Economics and Environmental Sociology, \\ University of Alberta, 515 General Services Building, Edmonton, AB T6J 2H1, Canada
}

\begin{abstract}
Across North America dairy processors are facing financial difficulties, yet a Canadian processor continues to grow through acquisitions of its competitors. This company, Saputo, grew up in a highly regulated marketplace where input raw milk supplies are restricted, input prices are inflated and imports of final product are restricted. This study asks if the Canadian system of dairy supply management prodded and assisted Saputo into making acquisitions at home and abroad. An empirical model estimates the probability of Saputo making acquisitions as a function of factors influenced by supply management and control variables accounting for Saputo's financial performance. The results indicate that cash flows, which may be increased by regulatory rents, and a measure of restrictiveness of the Canadian milk supply, both are statistically significant positive determinants of the probability that Saputo will make an acquisition. On average over the estimation period removing the Canadian supply managed regime would reduce the probability of acquisitions by $7 \%$. The implication is that the Canadian system is losing investment and employment opportunities by retaining its restrictive regulatory system.
\end{abstract}

Keywords: agribusiness, post farm gate, dairy processing, acquisitions, logit model JEL code: Q13, Q14

(1)Corresponding author: egoddard@ualberta.ca 


\section{Introduction}

Canada does not have very many industrial champions; let alone champions in the agrifood sector. Saputo Inc. has grown from a family-owned enterprise, delivering mozzarella cheese door to door by bicycle, to the world's ninth largest dairy processor. It initiated this growth in a sector that is viewed as over-regulated, and highly protected with no room to grow (Carter and Mérel, 2016). An alternative view might be that Canada's supply management system has unintentionally motivated and supported Saputo's growth in global markets.

The current regulatory system governing Canada's dairy industry traces its origins to the 1960s. While primary milk production has become highly profitable because of the pillars of supply management - restrictive import controls, administered pricing and production controls - it is not clear what the impact of these factors is for processors. The system may penalize profitability because of the regulations that processors face, including higher input prices, restrictions on their input use and ultimately constraints on their growth.

On the other hand, domestic processors profit from reduced import competition and the concentrated nature of the industry that allows the high cost of milk to be passed on to consumers. The economic rents from high retail prices are captured by retailers and in turn shared with processors (Pouliot and Larue, 2012). Dairy processing requires significant up-front capital investments. Economic rents provide a source for this up-front capital. Furthermore, the regulatory structure reduces the production and market risks that dairy processors, including Saputo, face in Canada. The managed nature of the regulated market guarantees input prices and volumes of raw milk are predictable. In Canada, where Saputo accounts for roughly one third of cheese and fluid milk/ cream production, its leading position and economies of scale have been protected by a raw milk allocation system that guarantees milk to the nation's existing processors. A combination of growing production volumes plus high operating leverage benefits the company with further potential scale economies (Lash, 2019).

Saputo Inc. appears to be more successful than its major North American competitors. Dean Foods Co. is the largest U.S. milk producer and owner of 50 brands. Yet Dean is facing severe financial difficulties and has filed for bankruptcy and was sold to Dairy Farmers in America in April 2020 (Businesswire, 2020). Kraft Heinz Company was formed in a 2015 merger resulting in an arsenal of iconic brands, yet it has suffered a major loss due to the write-down of its Kraft brand. In contrast, Saputo's global sales have more than doubled over the last decade and, aside from two failed acquisitions in Germany and Wales, it has pursued a string of more than 30 successful acquisitions that have given it a significant presence in the global market (Saputo 2019).

Most economic analysis of the relationship between foreign direct investment (FDI) and food processing starts from the question of whether FDI and trade are complements or substitutes (Gopinath et al., 1999). However, given Canada's limited potential to export dairy products and the notion that Canada's supply managed system has encouraged FDI by Canadian dairy processors (Standing Senate Committee on Agriculture and Forestry, 2018), the trade-offs between FDI and trade are not that relevant to this paper. Rather the relevant considerations are whether foreign acquisitions allow parent companies to be globally competitive by accessing resources and taking advantage of lower costs of inputs provided in the host country (Hajderllari et al., 2012). This is the starting point for this paper.

What has led to Saputo's international success? This paper examines Saputo's growth in the context of the regulatory framework of Canadian supply management. It posits that this framework may allow Saputo to capture economic rents and that these rents helped the firm to acquire competitors and thereby further its growth. These rents are manifest as additions to free cash flow. The study empirically tests if free cash flow or a tightening of production quotas for Canadian raw milk affect the probability of Saputo making foreign or domestic acquisitions. Foreign acquisitions are of particular interest because with supply management there is limited room for Saputo to grow in the Canadian market. Furthermore, Canada has recently signed several regional preferential trade agreements that incrementally open the Canadian market to slightly more competition, encouraging Canadian companies to look at growth in other countries. 


\section{Regulatory structure}

Saputo grew up in a sector, protected by prohibitive import barriers, with a limited number of domestic competitors, and the potential to capture economic rents that could be used to further its growth. Canada's system of supply management provided both a protective structure for the company to grow but also constraints that ultimately limited its domestic growth potential.

The current regulatory system for Canadian dairy began with the 1966 establishment of the Canadian Dairy Commission (CDC) (Van Kooten, 2020). This was followed in 1970 by the introduction of a National Milk Marketing Plan to control supply and in 1972-73 market sharing quotas were established province by province. Supply management provides centralized provincial marketing boards with effective monopoly power where their major function is to limit marketed farm supplies by applying production or marketing quotas in order to achieve higher prices and revenues. The CDC coordinates with provincial marketing boards to set a target farm-gate price based on a survey of production costs. This target price allows the CDC to calculate support prices for butterfat and skim milk powder (SMP), and the agency agrees to purchase any surplus butter and milk powder at those prices. Each year the Canadian Milk Supply Management Committee (CMSMC) sets a quota on industrial milk based on expected sales and wholesale prices, allocating this quota to provinces based on historical market shares (CDC, 2019). Industrial milk is allocated to processors based on provincial allocation rules. The risk of an existing processor losing a significant share of its available industrial milk volume is negligible.

Canada regulates its dairy sector by using both import quotas (tariff rate quotas) and domestic production quotas, which limit the production of milk. Tariff rate quotas (TRQ) are two tier tariffs that allow import volumes up to a set level (quota) to be assessed at relatively low (in-quota) tariff, whereas imports beyond this volume pay a much higher (over-quota) tariff. Canadian TRQs have quotas sufficiently small so that they are filled and prohibitive over-quota tariffs apply to any incremental imports. As a result, over quota imports do not occur and the TRQs act like traditional import quotas. Canada and the US notified a number of over-quota tariffs and quota volumes for dairy products to the World Trade Organization (WTO) (Table 1). ${ }^{1}$ The Canadian WTO TRQ volumes applied pre-URAA import quotas and most $(75 \%)$ of these quotas are allocated to non-processor importers (CITT, 1992).

TRQs affect Saputo in two different ways. First, the prohibitive border measures allow Saputo to sell their products in a highly concentrated market. Second, although Saputo does hold a small share of the preferential cheese TRQ allocation and distributes European cheeses through its network, this share is estimated to represent less than $4 \%$ of its dairy sales. ${ }^{2}$ Therefore, any economic rents derived from preferential access to imported cheese are considered very small and not included in the rest of the analysis.

Table 1. World Trade Organization over-quota tariffs and quotas (Business Development Bank of Canada, 2019; GAC, 2019, USDA-FAS, 2019; USITC, 2019).

\begin{tabular}{|c|c|c|c|c|}
\hline & \multicolumn{2}{|l|}{ Canada } & \multicolumn{2}{|l|}{ US } \\
\hline & Tariff over-quota (\%) & Quota (tons) & Tariff (\%) & Quota (tons) \\
\hline Fluid milk & 241 & 64,500 & 35 & 11,356 \\
\hline Yogurt & 237 & 332 & 20 & $\mathrm{NA}^{1}$ \\
\hline Cheeses & 245.5 & 20,412 & $17-35$ & 136,441 \\
\hline Butter & 298.5 & 1,914 & 20 & 6,974 \\
\hline
\end{tabular}

${ }^{1} \mathrm{NA}=$ not available.

\footnotetext{
${ }^{1}$ Recently negotiated preferential regional trade agreements (CETA and CPTPP) have added 19,051 tons of additional imported cheeses to the inquota volume. Global Affairs Canada (2019) provides a list of Cheese Quota Holders which grows to 34,202 after implementation period.

${ }^{2}$ Saputo's 2000 annual report states that $11 \%$ of its Canadian dairy sales were made up imported cheese, evaporated milk and grocery products. Accounting for non-dairy products the share of imported cheeses is roughly $4 \%$ of sales. Recent CETA and CPTPP TRQ allocations did allocate $20 \%$ of the additional 19,051 tons of cheese to Saputo, Agropur and Parmalat Canada Inc. However, these changes occur after our estimation period and are not considered.
} 
Saputo started life in a domestic market with production controls, with concerns about inefficient scale, constraints on growth, extensive regulation and high input prices. However, some of these constraints also offer intangible benefits. The regulatory environment has led to a non-competitive market structure for dairy processors. This is because Canadian milk production is allocated to processors based on allocation rules for milk for each province, with each processor receiving a certain quantity of raw milk to process. This poses a barrier for new entrants because they would need to purchase plant supply quotas (where available) from existing processors. While any market power would likely be limited by the commodity nature of the market, it probably modestly enhanced Saputo's historical returns allowing it to grow through acquisitions (Lash, 2019).

Consider a very stylized vertical model of the Canadian dairy sector (Figure 1). ${ }^{3}$ The CMSMC sets an annual industrial milk production quota which is equal to $Q_{0}$. Raw milk is converted to a final dairy product through a fixed proportions technology. This product passes through two levels of the stylized market - processing and retailers who sell it to final consumers. Even though processors and retailers have very little to say over the volume of dairy product produced, we would expect processing and retailing economic rents to be determined endogenously. Saputo sells $47 \%$ of its cheese through retail outlets (grocery stores and other smaller shops) and remainder through institutional channels (Saputo, 2019). The size of the rents depend on how concentrated each sector is. Both the Canadian retail grocery ${ }^{4}$ and processing sectors are highly concentrated. Pouliot and Larue (2012) developed a bargaining power model of the supply managed chicken industry that allocated economic rents between the retail and processing market. We adopt an alternative top-down recursive approach to determine the distribution of economic rents.

Starting with a price dependent retail demand curve and a fixed level of dairy production, $Q_{0}$, the retail price, $P^{r}$, is determined by retail consumers' willingness to pay which is established at this intersection. The retail marginal revenue curve $M R^{r}=\operatorname{Pr}\left(1+\left(s^{r} / \eta^{r}\right)\right)$ determines the economic rents that individual retailers can capture $\left(P^{r} a b P^{p}\right)$. The size of the rents depends on the retail marginal revenue curve which is turn is a

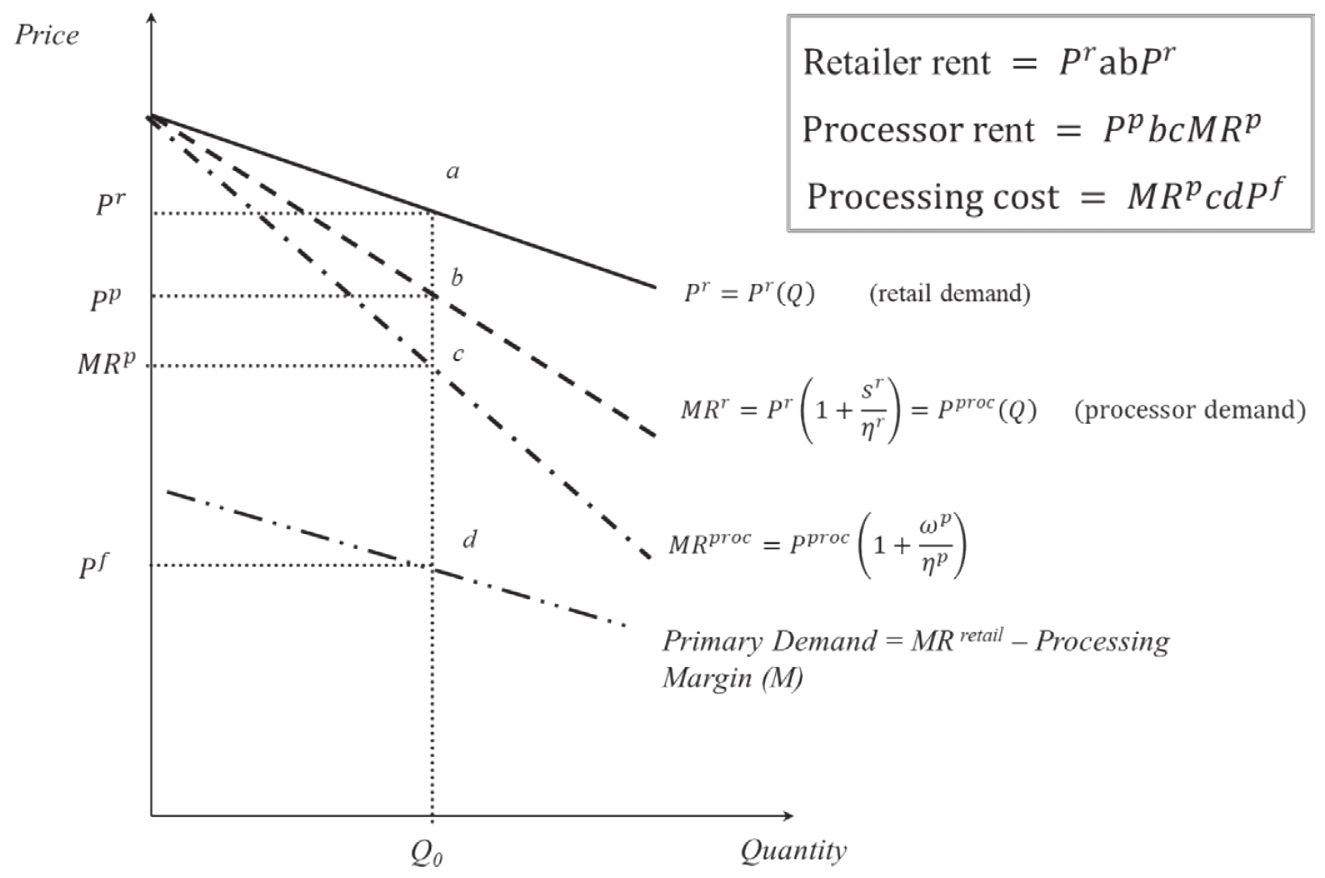

Figure 1. Disposition of economic rents as associated with production quotas.

\footnotetext{
${ }^{3}$ Details about the market have been suppressed including farm level marginal cost, and associated production quota rents. In addition, the effects of imports administered through the TRQ system has also been supressed as well given the small role that imports play in Saputo's domestic operations.

${ }^{4}$ This sector is very concentrated with the 5 top firms accounting for well over $80 \%$ of the market.
} 
function of a Cournot oligopolist's decision rule where $s^{r}$ is the market share of a representative individual retailer and $\eta^{r}$ is the retail demand elasticity.

The non-competitive market structure for processors is reinforced by provincial raw milk volume allocation rules $^{5}$ which dictate the volume of processed dairy products and economic rents are available to agents in the market. Processors are also assumed to act as Cournot oligopolists. The processing marginal revenue curve $M R^{p}=P^{P}\left(1+\left(\omega^{p} / \eta^{p}\right)\right)$ determines the economic rents that individual processors can capture $\left(P^{p} b c M R^{p}\right)$, and where $\omega^{p}$ is the processor's share of the market and $\eta^{p}$ is processor level elasticity of demand. The processor rents available for Saputo to capture grew as the scale of domestic operations grew with the acquisition of smaller Canadian processors (between 1997 and 2019 Saputo acquired 11 Canadian firms in different regions of the country).

Finally processing costs $\left(M R^{p} c d P^{f}\right)$ reflect increasing returns to scale in the processing sector. With increasing returns to scale, unit processing costs decline as the scale of output increases. ${ }^{6}$

The presence of processing profits is not a sufficient condition for foreign acquisitions. Certainly, the presence of rents could facilitate cash acquisitions or improved borrowing terms for debt acquisitions, but the major driver for acquisitions outside of Canada is likely that there was nowhere to grow in Canada after opportunities for new domestic acquisitions were exhausted. China is no doubt the biggest potential growth market but accessing this market requires raw milk capacity outside of Canada, in countries with preferential access to Chinese markets, and this requires foreign acquisitions.

\section{Competitors and company history}

\subsection{International competitive environment}

In 2019 Saputo was listed as the ninth largest dairy company in the world with \$US 11 billion in sales while Dean Foods was listed two spots lower at number 11 with \$US 7.5 billion in sales and Kraft-Heinz was listed at number 14 with \$US 6 billion in sales (Rabobank, 2019). Saputo has a 37\% share of Canadian milk and cream production, a $32 \%$ share of Canadian cheese production, and a $9 \%$ share of U.S. cheese production (Lash, 2019). Saputo commands a leading market share in the U.S. and Canada, with consistently strong capacity utilization, and efficient production processes. Saputo's major Canadian competitors are the Quebec cooperative Agropur and Parmalat Canada which is owned by the French conglomerate 'Groupe Lactalis'. Together they utilize most of the Canadian milk supply. Agropur also has made acquisitions to give them a significant presence in the U.S. market, and in fact has competed in the same regional markets, as Saputo, to acquire these plants.

In terms of international competitors for acquisition targets, since Saputo entered Rabobank's 'top twenty' processor list in 2003, four companies have topped the Rabobank list: Nestlé, Danone, Lactalis, and Fonterra. Until 2014, the majority of Saputo's international acquisitions were located in the upper mid-west of the U.S. Nestlé is a global conglomerate producing a broad variety of confections and foods. Nestlé North America's operations primarily focus on the production of frozen desserts and it does not have a presence in other dairy products (Canning, 2018). Nestlé cannot be considered a major competitor for the acquisition of existing U.S. plants. Likewise, Danone was not a major competitor with respect to acquiring cheese processing plants. Danone has 13 U.S. plants producing mostly yogurt and yogurt-based drinks (Canning, 2018). Danone has made major in-roads in Asia through joint ventures (Guyonnet, 2016). Again, although Danone was a competitor for milk supplies, it was not a competitor for acquiring U.S. operations.

\footnotetext{
${ }^{5}$ The exact process is more complicated. Both fluid and industrial milk are allocated to the processor. The allocation of industrial milk is complex managed system known as plant supply quotas (Dairy Farmers of Ontario, 2006)

${ }^{6}$ The gap between $M R^{P}$ and $P f$ may include more than Saputo's unit processing costs, since the regulatory system allows the assessment of an 'assumed processing allowance'. Technically the lucrative allowances overcompensate for processing costs and should be considered part of the processor rents.
} 
Both Fonterra Cooperative Group and Lactalis offer more direct competition for Saputo, however neither has a large presence in the U.S. market (Canning, 2018). Although Lactalis is a major player on world markets and in Canada (i.e. Parmalat Canada), the company only has five regional U.S. plants (California, Idaho, New York, and Wisconsin). Before Saputo's expansion into Australia in 2014, its acquisition strategy was to seek out similar operations to its own which were 'inefficient or loosely run with mediocre operating margins' (Willis, 2019). This strategy did not put Saputo in direct competition with Lactalis (outside of Canada). The strategy used by Lactalis has no geographic limits, and its acquisitions are focused on Latin America, Europe, Russia, Saudi Arabia, India, South Africa and Australia (Guyonnet, 2016). It is in Australia that Lactalis and New Zealand's Fonterra Cooperative group compete most directly with Saputo for the Australian national milk pool to produce products that are increasingly destined for China (Guyonnet, 2016).

\subsection{Company history}

Between 1970 and 1997, Saputo acquired several Canadian production operations and food distributors, and developed its national distribution network and in the process positioned itself as a major producer of mozzarella. During that time it grew as a restaurant supplier, buying up small cheese plants in Quebec and Ontario and then plants in Vermont, Wisconsin and California. In 1988, Saputo entered the U.S. with its first acquisition (Saputo, 2011). In 1997, Saputo moved from being a private family-owned company to a publicly traded firm and in October 1998 completed an initial public share offering.

Since going public Saputo has made over 20 acquisitions (Table 2). This table distinguishes between domestic and foreign acquisitions. To simplify the exposition, acquisitions are grouped across time periods. However, several notable acquisitions are identified separately.

Though predominately a cheese maker, Saputo entered the multiproduct world of dairy products with the acquisition of its first fluid milk plant in 1997. Saputo broadened its product base with the Canadian acquisition of Dairyworld Foods (acquired in 2001) and Neilson Dairy (acquired in 2008). Since 1997, the company has pursued an aggressive agenda of acquisitions, starting with the Canadian market, branching out to the US, and finally seeking offshore growth with 62 plants on five continents (Saputo, 1998-2020). The growth has been through acquisitions and not through green field investments. Typically, Saputo targets those companies that complement its own activities (e.g. cheese making). After an acquisition, they quickly attempt to integrate the target by upgrading and modernizing (Willis, 2019). They are able to make these investments because of their substantial resources and deep pockets. For example, a typical investment is in the technology to maximize the yield of cheese for a given amount of milk (Lash, 2019). Anecdotal evidence suggests that Saputo has the highest cheese yields in North America. They certainly have acquired a reputation for operational excellence with a focus on low-cost leadership (Sparling, 2014) and have achieved success in turning around acquired firms by starting from an operating standpoint (Kirby, 2019). In fiscal 2019, Saputo operated 27 facilities in the U.S. with an overall excess capacity of $12 \%$, suggesting capacity utilization of close to $90 \%$ (Lash, 2019).

Table 2. Acquisitions over time (US\$ millions) (Saputo, 1998-2020).

\begin{tabular}{lll}
\hline & Domestic & Foreign \\
\hline $1997-2006 / 07$ & 7 acquired (\$561 million) & 8 US acquired (\$509 million) \\
$2007-2012$ & 1 acquired (\$449 million) & 4 US acquired (\$701 million) \\
& & 1 UK acquired (\$11.52 million) \\
2012 & & Morningstar US (\$1.45 billion) \\
2014 & & Warrnambool Cheese \& Butter Aus. (\$560 million) \\
$2014-2017$ & 2 acquired (\$193 million) & 2 US acquired (\$325 million) \\
2018 & & Murray Goulburn Aus. (\$1.1 billion) \\
$2018-2019$ & 1 acquired (\$76 million) & 1 US (\$ 86 million) \\
& & Dairy Crest UK (\$1.3 billion) \\
\hline
\end{tabular}


Saputo's economic performance has continuously improved since it became a publicly traded company in 1997 (Table 3). Between 1997 and 2018, Saputo has achieved exceptional growth with revenues growing more than $560 \%$ and assets growing $570 \%$. Much of the foundation for this growth was preceded by frenzied acquisition activity with 18 acquisitions in the first 10 years after Saputo went public.

Many of the acquisitions were made in the 2003-08 period when the company's debt levels were historically low and their free cash flow was doubling every five years. Over this period, the company was able to consolidate its manufacturing facilities and acquire U.S. regional players to maximize its capacity utilization, thereby creating free cash flow. Admittedly, the largest valued foreign acquisitions have occurred since 2012 with slower growing, and eventually declining, free cash flow and rapidly growing debt. Nonetheless, over this 20 -year period while assets grew by 6.7 times, long-term debt has only grown by four times while interest rates remained at historically low levels.

Consequently, as they have ventured abroad Saputo has done so with deep pockets. Figure 2 plots annual foreign and Canadian acquisitions by their acquisition prices. It should be noted that pre-2008 acquisitions were cash based and the majority of the acquisitions were debt free.

Table 3. Saputo's financial position over time (US\$ millions) (Barchart, 2019).

\begin{tabular}{lrrrrrrr}
\hline & $\mathbf{1 9 9 7 - 0 2}^{\mathbf{1}}$ & $\mathbf{2 0 0 3 - 0 8}^{\mathbf{1}}$ & $\mathbf{2 0 0 9 - 1 4}$ & $\mathbf{2 0 1 5}$ & $\mathbf{2 0 1 6}$ & $\mathbf{2 0 1 7}$ & $\mathbf{2 0 1 8}$ \\
\hline Income statement & & & & & & & \\
$\quad$ Revenue & 2,043 & 3,986 & 6,848 & 10,992 & 11,163 & 11,543 & 13,502 \\
$\quad$ Expenses & 1,944 & 3,767 & 6,430 & 10,391 & 10,435 & 10,690 & 12,747 \\
$\quad$ Net income & 99 & 220 & 418 & 601 & 728 & 853 & 755 \\
Balance sheet & & & & & & & \\
$\quad$ Assets & 1,480 & 2,275 & 4,261 & 7,172 & 7,597 & 8,003 & 9,886 \\
$\quad$ Liabilities \& equity & 1,480 & 2,275 & 4,261 & 7,172 & 7,597 & 8,003 & 9,886 \\
$\quad$ Debt & 479 & 296 & 722 & 1,208 & 1,500 & 1,421 & 1,944 \\
Cash flow & & & & & & & \\
$\quad$ Free cash flow & 113 & 201 & 434 & 615 & 752 & 465 & 449 \\
Acquisitions & 6 & 12 & 5 & 2 & 0 & 2 & 3 \\
\hline
\end{tabular}

${ }^{1}$ Values are averaged over the defined period.

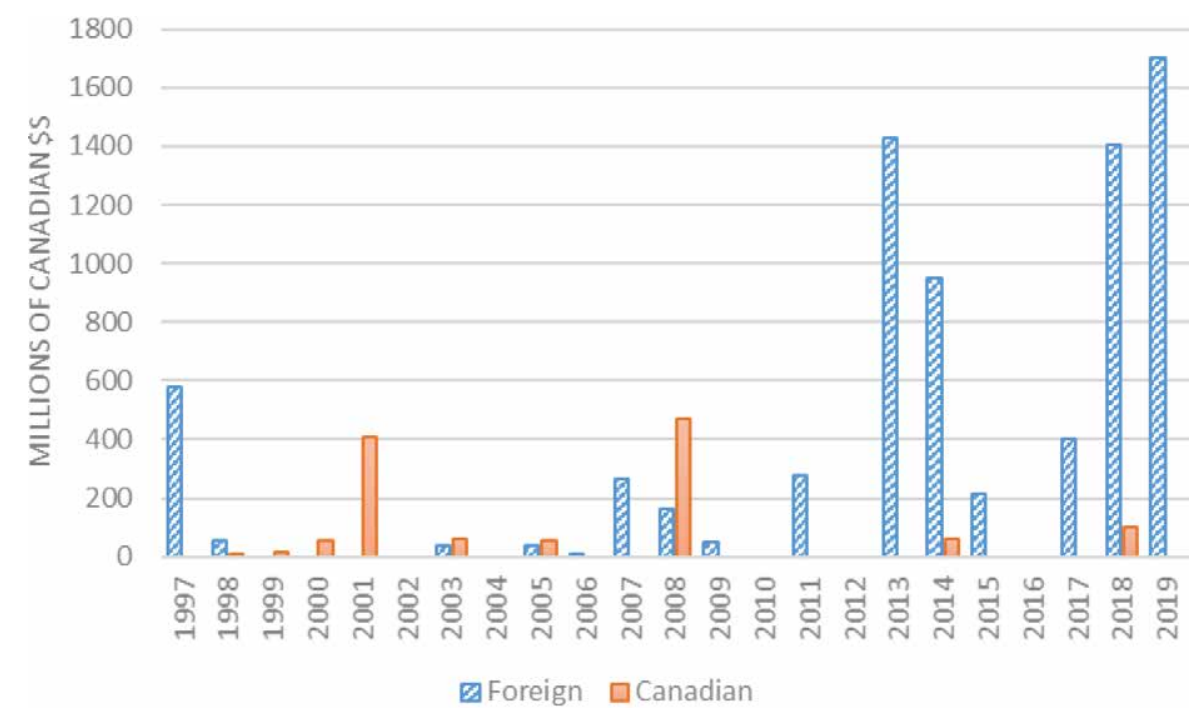

Figure 2. Saputo's annual acquisitions: foreign and domestic. Acquisitions pre-2008 were cash based. 
The question is whether this cash came from being the low-cost producer or whether Saputo been able to capture rents, associated with the Canadian system of supply management, and used these rents to finance their growth remains open? Certainly, if Saputo wanted to grow, in terms of volume of sales, the company had to seek markets outside of Canada.

\section{Empirical strategy and data}

The empirical model attempts to study if there is a relationship between Saputo's free cash flows and its acquisition behavior. A significant positive relationship is the necessary condition for Saputo to have used economic rents from within the Canadian supply management system to facilitate acquisitions. The discussion includes the specification of an econometric model, the selection of a set of potentially relevant explanatory variables, sources of data, and estimation method.

The empirical objective is to explain the probability that Saputo will acquire another firm. Since this decision process involves a probability, it is modeled with either a probit or logit model. ${ }^{7}$ Logistic regression applies maximum likelihood, after transforming the dependent into a logit variable (i.e. the natural logarithm of the odds of the observation involving an acquisition), to estimate the changes in the log-odds of the dependent variable. In this case the dependent variable is the probability that Saputo acquires another firm (acquisition is the dominant form of activity by Saputo in their mergers and acquisition strategy).

Despite the volume of empirical studies examining acquisition activity there is no well-defined general theory of all of the competing underlying causes of mergers and acquisitions (Gorton et al., 2009). However, the literature provides some guidance for discovering factors that help explain acquisition decisions and the probability that a firm will acquire another firm or merge. Goldberg (1983) describes motives for agrifood mergers and acquisitions including: growth, scale economies, profitability, market share, market power, synergy, acquisition of specific assets/products, and increased resource utilization. The most common reason, in the literature, is the search for synergies between firms. Empirically this requires examining both parties to a transaction. Although cross-sectional studies can potentially account for both sides of a transaction, in this case we use time-series data and are only concerned with a single firm. Therefore, we follow Richards and Manefredo (2003) and focus on the motivations of the acquiring firm which are structural (influencing the financial ability to acquire other firms) and macroeconomic (trends in sectoral acquisitions and overall economy) factors.

The firm's ability to take advantage of acquisition opportunities depends on the state of its balance sheet which can be represented with a series of financial ratios which capture structural factors. Financial ratios can be divided for convenience into: liquidity, activity, debt, profitability and market ratios (see Gitman and Zutter, 2015 for a complete list). Palepu (1986) used several firm level accounting and stock market performance variables to predict takeovers. Liquidity ratios and leverage ratios measure the adequacy of a firm's capital base (Adelaja et al., 1999) and its ability to seize an opportunity. Profitability ratios provide a snapshot of company's financial health, they are a bottom line for investors and are widely used across empirical studies of acquisitions. Cash-richness helps to predict whether a firm will become a bidder. It is consistent with the predictions of the free cash flow hypothesis (helps to explain agency conflicts between manager and shareholders). Hartford (1999) added a variable for the difference between a firm's cash reserves and the amount predicted by cash management models.

Macroeconomic trends fuel expectations about future growth opportunities, conditions in the home market of the targeted firm and may reflect trends in overall acquisitions in the sector, and possibly the overall economy.

\footnotetext{
7 We have received suggestions for an identification strategy to isolate and identify the impacts of supply management versus managerial skills on acquisition decisions that would employ a panel of data across competitors (e.g. Agropur, Lactalis, and Fonterra). In theory this approach is appealing. However, equivalent data for these companies is not available so the approach is not feasible.
} 
A small number of agribusiness studies have used firm level cross-sectional (or panel) data to examine merger and acquisition activities in US food processing. Adelaja et al. (1999) predicted the likelihood of a firm being targeted for takeover. The firm level structural factors that they identified associated with a targeted firm included: liquidity problems, an inverse relation between leverage and the likelihood of being targeted, activity ratios, profitability, size, growth, dividend policy and stock market characteristics. ${ }^{8}$ Although Adelaija, Nayga, and Farooq identified factors for potential take-over targets, most of the same factors apply to acquisitor firms, but with opposite expected signs.

Richards and Manfredo (2003) examined cooperative merger and acquisition activity with respect to macroeconomic and structural factors with an emphasis on the role of capital constraints. ${ }^{9}$ While predicting merger and acquisition activity their explanatory reasons for consolidation included the following structural factors: cost reduction (asset turnover ratios); revenue enhancement (sales growth); profitability (return on assets) and extent of capital constraints (current ratio). ${ }^{10}$ They included additional macroeconomic variables (growth rates for gross domestic product (GDP), the value of agriculture production, and a measure of overall agribusiness merger and acquisition activity).

The data used in this study was drawn from Saputo's quarterly and annual financial reports (Table 4). In addition to the explanatory variable of primary interest real cash flows, we follow the prior literature and examine two types of variables - structural firm specific variables and sector wide macro variables. The estimation period extends from the second quarter of 1997 to the last quarter of 2018. All acquisitions are counted as occurring in the quarter that they were announced as recorded in Saputo's annual reports. Although typically the actual acquisition was not finalized until a later date, we believe the appropriate timing for this analysis is as near to the point where the decision was made. No acquisitions were announced and then not completed in any of the Saputo official documents. Quarterly financial data comes from Saputo's quarterly income statements, cash flows and balance sheets (Barchart, 2019). All variables recorded in levels were converted to constant US dollars with an appropriate CPI. The period between the point at which the acquisition was announced and when the decision to acquire involves a lag. We employed a minimum Bayesian Information Criterion to allow the data determine the appropriate lag length. As a result, all the variables hypothesized to affect the probability of acquiring other firms are lagged five quarters. We introduce a set of control variables that are based on prior agribusiness acquisition literature. We have eliminated several short-term liquidity and activity variables that we considered, tested, found insignificant and dismissed (Table 4). In terms of leverage, a highly leveraged firm is less likely to be a bidder (Lintner, 1971) because it is likely looking to borrow money to expand operations and would likely avoid other highly leveraged firms. We consider Saputo's long-term debt to equity ratio to account for leverage. Finally, in terms of acquisition destination characteristics we include U.S. GDP growth rate, the growth rate for U.S. cheese consumption and a dummy variable accounting for offshore acquisitions.

To account for profitability, we include Saputo's return on equity. To account for the owner's appraisal of Saputo's value we include a price to earnings ratio. We also include an abnormal return variable (Hartford, 1999) which is determined as the residual when Saputo's share price is regressed on the S\&P index for Canadian consumer goods (Barchart, 2019). This residual is averaged over the last five quarters and gives an indication of the market's evaluation of Saputo's profitability relative to close competitors.

\footnotetext{
${ }^{8}$ Adelaja, Nayga, and Farooq found significant liquidity variables (quick ratio) but with the wrong sign; significant leverage effects (long term debt to equity); significant profitability (return on equity); growth (growth on sales); stock earnings capacity, percentage of common stocks traded (ratio of common stocks traded) and market to book ratios. Factors that were not significant included activity ratios, firm size, and price to earnings ratios. ${ }^{9}$ Significant variables included profitability (return on assets) and extent of capital constraints (debt to asset ratio was significant with the correct sign while the current ratio was significant but wrong sign). Other structural factors that were insignificant including cost reduction (asset turnover ratios) and revenue enhancement (sales growth). They included additional macroeconomic variables (GDP and sector growth, and overall agribusiness merger and acquisition activity).

${ }^{10}$ Variables that did not appear as statistically significant explanatory variables included firm size, activity measures, return on assets, sales growth, and price earnings variables.
} 
Table 4. Summary statistics of quarterly variables used in estimation procedure (FRED, 2019; Saputo, 1998-2020; Statistics Canada, 2019).

\begin{tabular}{llllll}
\hline Variable & Mean & Std. Dev. $^{\mathbf{1}}$ & Min. & Max. & Observations \\
\hline Acquisitions & 0.280 & 0.452 & 0 & 1 & 82 \\
Cash (million US\$) & 10.874 & 7.511 & 0.158 & 34.810 & 82 \\
Exchange rate (C\$/US\$) & 1.245 & 0.193 & 0.964 & 1.594 & 82 \\
Debt/equity (ratio) & 0.480 & 0.277 & 0.092 & 1.115 & 82 \\
Price/earnings (ratio) & 20.253 & 4.461 & 13.550 & 33.130 & 82 \\
Growth milk quota & 0.005 & 0.048 & -0.084 & 0.116 & 82 \\
Return on equity & 0.025 & 0.009 & -0.001 & 0.067 & 82 \\
\% $\Delta$ US cheese use & 0.006 & 0.01 & -0.02 & 0.03 & 82 \\
Turnover & 5.297 & 3.194 & 3.25 & 9.5 & 82 \\
Current ratio & 1.622 & 0.277 & 1.087 & 2.2 & 82 \\
US prime (interest rate) & 5.29 & 2.194 & 3.25 & 9.5 & 82 \\
Canadian prime (interest rate) & 2.62 & 1.67 & 0.38 & 5.87 & 82 \\
US GDP ${ }^{1}$ growth & 0.005 & 0.006 & -0.02 & 0.02 & 82 \\
\hline
\end{tabular}

${ }^{1}$ Std. Dev. = standard deviation; GDP = gross domestic product.

Other non-financial variables are taken from a variety of sources. Although Saputo is a Canadian company the majority of its current production and sales occur in the US (Figure 2). To account for the effect of currency fluctuations on revenues, expenses and investment decisions, a five-quarter lag of the Canada/US exchange rate is included in the specification (FRED, 2019). A major constraint for Canadian operations is milk production quotas. To account for the variety of production quotas across provinces, the rate of growth of the total volume of milk produced on farms (Statistics Canada, 2019) and labeled as 'quota' is used as a proxy for any relaxation in production quotas. It is expected that as Canadian production quotas are relaxed Saputo would have less incentive to seek acquisitions. While prior studies used cross sectional data across firms to predict acquisitions, since we are focusing exclusively on Saputo the data is time series. Discrete choice models can include a threshold-crossing specification where a dummy variable indicates an affirmative choice decision in the previous period (Honoré and Kyriazidou, 2000). Under structural state dependence if an affirmative choice has not been made in a previous period it is more likely that it will be made this period, and conversely if an affirmative choice was made the previous period it is less likely that the same choice will be made this period. In the context of acquisitions if Saputo purchased a firm in a previous period, because of increased financial and administrative burden, it is less likely to make an acquisition this period. We have included a dummy variable which accounts for an acquisition in the previous period to account for these threshold-crossing considerations.

\section{Empirical results}

\subsection{Estimation results}

The objective of the empirical model is to determine if there is a significant relationship between free-cash flow and the probability of Saputo acquiring a competitor. Given the logistical regression specification described above the results are presented in Table 5. Tests employing variance inflation factors (VIF) were used to detect multicollinearity among the explanatory variables. The mean VIF was 1.41 and the VIFs for all variables were well within acceptable limits so collinearity does not appear to be a problem. Visual inspection of the data did not reveal any discernable outliers among the explanatory variables. ${ }^{11}$ Next a specification test of functional form was conducted that tests the left-hand side of the equation (i.e. Link equation). The

\footnotetext{
11 Since the analysis involves time series data it is reasonable to inquire about the stationarity of the data. By design most of the data (ratios and growth rates) will not exhibit stochastic trends. The one possible variable of concern is current cash flows. An augmented Dickey-Fuller test found that we can reject the null hypothesis that cash flows exhibit a unit root.
} 
Link test includes combinations of predicted values, as explanatory variables, with the null hypothesis is that the original specification is appropriate. These additional combinations of the predicted variables were not significant and the null hypothesis couldn't be rejected. Although this is not a complete model specification test, if we were to reject the null hypothesis this would certainly have led us to question if we have included all the relevant variables. Finally, it is necessary to test for autocorrelation to ensure that the threshold variable is contemporaneously independent of the current error term. If it is contemporaneously independent than the estimator is asymptotically consistent. ${ }^{12}$ We have tested for autocorrelation with a Durbin- $\mathrm{h}$ test $(\mathrm{h}=0.006)$ and could not reject the null hypothesis of the absence of autocorrelation. ${ }^{13}$

The specification fits well and all of the parameters together are jointly significant (likelihood ratio chi-square of 42.41 with a $P$-value of 0.000 ). McFadden's pseudo $\mathrm{R}^{2}$ is reasonable for the fit of a model of this type. Of the ten explanatory variables, four are significant at least at the 5\% level, two are significant at the $10 \%$ level and the return on equity is almost significant at the $15 \%$ level. Together all of the financial variables are jointly significant $\left(\mathrm{Prob}>\mathrm{chi}^{2}=0.009\right)$.

Consider two types of coefficients - the raw coefficients from the regression and the marginal effects (Table 5). The marginal effects give the average effect of changes in explanatory variables on the change in the probability of an outcome. Marginal effects provide a direct and easily interpreted prediction of the probability for a unit change in an explanatory variable.

The results (Table 5) provide evidence that Saputo was more likely to acquire competitors when it had more cash on hand. For one million dollars of additional cash, the probability of making an additional acquisition increases by $2.2 \%$ points. Lower availability of Canadian milk also increases the probability of an acquisition by $1.9 \%$ points, for a $1 \%$ contraction in the Canadian milk supply.

In terms of the control variables we do not list all possible financial control variables (Table 5). A number of additional control variables were considered, found to be insignificant and not included in Table 5. These

Table 5. Parameter estimates for logit model. ${ }^{1}$

\begin{tabular}{lllll}
\hline & Coefficient & Std. Error & Marginal effect & Std. Error \\
\hline Return on equity & 0.337 & 0.244 & 0.029 & 0.023 \\
Price/earnings & $0.261^{* * *}$ & 0.098 & $0.023^{* * *}$ & 0.010 \\
Debt/equity & -2.075 & 1.781 & -0.180 & 0.154 \\
Cash & $0.221^{* * *}$ & 0.074 & $0.019^{* * *}$ & 0.008 \\
Exchange rate & $5.44^{* *}$ & 2.946 & $0.474^{* *}$ & 0.263 \\
Canadian milk quota & $-13.74^{*}$ & 7.69 & $-0.019^{*}$ & 0.007 \\
Growth US cheese & $-0.697^{*}$ & 0.431 & $-0.060^{*}$ & 0.031 \\
Threshold dummy & $-6.522^{* * *}$ & 2.144 & $-0.378^{* * *}$ & 0.317 \\
Dummy offshore & 1.78 & 1.392 & 0.274 & 0.316 \\
Dummy $(\$ 500$ million+) & -0.071 & 1.338 & 0.006 & 0.114 \\
Intercept & $-15.378^{* * *}$ & 4.661 & & \\
LR chi ${ }^{2}(10)=42.81$ & Prob $>$ chi ${ }^{2}=0.0000$ & & & \\
BIC $=-257.97$ & VIF (mean) $=1.41$ & & & \\
Pseudo ${ }^{2}=0.436$ & Dubin-h $=0.006$ & & & \\
I $^{* * *}{ }^{* * *}{ }^{*}$ denote rejection of null hypothesis at the 1,5 and $10 \%$ significance levels; BIC = Bayesian Information Criteria; VIF $=$ \\
variance inflation factors.
\end{tabular}

\footnotetext{
$\overline{12}$ We also employed a Durbin-Wu-Hausman test to determine if the threshold dummy variable is independent of the error term and therefore exogenous. We were unable to reject the null hypothesis is that particular explanatory variable is exogenous.

${ }^{13}$ Robust standard errors were also calculated and non-spherical disturbances were not found to be a problem.
} 
variables include liquidity and activity ratios (which are less relevant to long-term decision making), interest rates (both US and Canadian prime rates were considered), the growth rate of U.S. GDP and a measure of abnormal returns relative to firms in related sectors. Although the costs of raising capital do not appear to be important for Saputo, their effects may be off-set by cash reserves.

With respect to estimated control variables, a measure of profitability (return on equity) was only significant at the $15 \%$ level and has significantly less impact, in terms of marginal effects, than cash reserves have. The debt/equity variable was negative but not statistically significant. Debt may be less important for Saputo since many of the acquisitions were made with cash. Nonetheless, the sign is negative so the more leveraged that Saputo becomes the lower the probability that it will make acquisitions. A 1\% increase in the growth rate of U.S. cheese consumption translates into a $6.0 \%$ point decreased probability of Saputo making an acquisition. This variable is an indicator of the direction of the growth U.S. cheese market, where targeted firms are less willing to be acquired in a growing market. Exchange rates are a significant determinant for Saputo making acquisitions. An appreciation in the Canadian dollar increases Saputo's financial position at home, reduces the price of acquisitions in Canadian dollars, and this in turn increases the possibility that it will make acquisitions. Finally, two dummy variables were included to account for destination characteristics. The first dummy accounts for offshore non-North American acquisitions. The second dummy variable accounts for acquisitions over $\$ 500$ million. Neither dummy variable is statistically significant, but both are retained in the specification.

\subsection{Speculative assignment of impacts from supply management}

While the marginal effects (Table 5) can explain the probability of an acquisition as a result of a one-unit change in an explanatory variable, the model does not establish a causal relation between Canada's system of supply management and Saputo's acquisitions. Establishing such a causal relationship is beyond the scope of this paper because sufficient data necessary to econometrically identify the size of the quota rents and their contribution to free cash flow, is not available. ${ }^{14}$ The variable (in Table 5) with the most direct relationship to supply managed regulations is the growth rate of the Canadian milk supply. However, simply relaxing the size of the production quota would also reduce quota rents and in turn cash flows. Therefore, examining the impacts of supply management on Saputo's acquisitions requires a speculative exercise where cash flows are divided into those associated with quota rents and other sources of cash flow.

The speculative exercise begins with a conceptual model of the functioning of supply management and a three-step process to approximate the size of these quota rents. First, since cash flows (CF) are reported on a world-wide company basis, these values need to be prorated to only account for Canadian cash flows $\left(C F^{\text {Canada }}\right)$. Figure 3 presents a description of the Canadian shares of total Saputo global sales. These yearly shares are used to allocate total cash flows to Canadian and foreign markets. For the second step, rents are identified as a portion of the remaining cash flows. In Figure 1 processor rents are identified as ( $P^{p r o c}-$ $\left.M R^{\text {proc }}\right) \times Q$. After manipulation these economic rents are equal to $\omega / \eta \times C F^{\text {Canada }} 15$ where $\omega$ is Saputo's share of the Canadian cheese market $(\omega=32 \%)$ and $\eta^{p}$ is the absolute value of the wholesale elasticity of demand for cheese $\left(\eta^{p}=0.88\right) .{ }^{16}$ The third step removes the economic rents by adjusting cash flows by a multiple $(1-(0.32 / 0.88))=0.64$. So that post market-liberalization cash flows can be approximated as: $\left(0.64 \times\right.$ share $^{\text {canada }_{+}}$share non-canadian $) \times C F$.

\footnotetext{
14 It would have been ideal to construct a panel data set that accounted for the behaviour of Agropur, Lactalis and Fonterra. Data for the Canadian cooperative Agropur would have helped identify the cost efficiencies exclusive to Saputo, but unfortunately much of the required comparable data for such a joint estimation exercise is not available. International competitor comparisons would have helped identify the impact that supply management has on Saputo's investment decisions. Unfortunately, Lactalis is a privately owned company and Fonterra is not investor owned but is a cooperative, and therefore adequate data is not to conduct this type of analysis which identifies cross-firm drivers of acquisition decisions.

${ }^{15}$ Processing firms are assumed to adopt Cournot behavior where $M R^{\text {proc }}=P^{\text {proc }} \times(1+\omega / \eta)$. So $\left[P^{\text {proc }}-P^{\text {proc }} \times(1+\omega / \eta)\right] \times Q$ equals $P^{\text {proc }} \times Q \times(\omega / \eta)$. A further approximation is that $P^{p r o c} \times Q \times(\omega / \eta)=C F^{\text {Canada }} \times(\omega / \eta)$.

16 The wholesale demand elasticity is derived as a fixed proportions derived demand $\eta^{\text {proc }}=\eta^{\text {retail }} \times p^{p r o c} / P^{r e t a i l}$. The retail demand for elasticity is -1.22 and obtained from Veeman and Peng (1997). The ratio of wholesale to retail prices is approximately 0.72 so that $\eta^{\text {proc }}=-0.88$.
} 


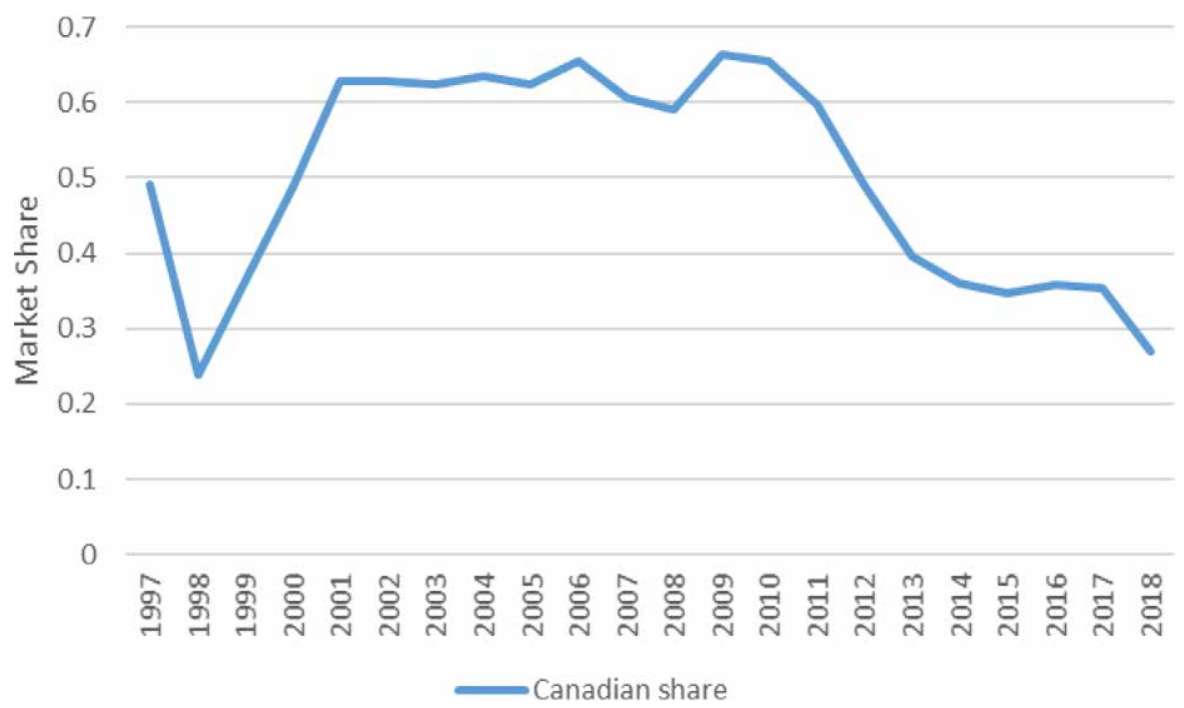

Figure 3. Canadian share of Saputo's annual sales.

Returning now to the growth rate of the Canadian milk supply, which should concurrently affect Saputo's decision to acquire existing processors either in Canada or aboard, we consider relaxing milk production quotas. Certainly, overtime Saputo was limited in its growth by production quotas and sought additional raw milk through acquisitions. Relaxing Canadian production quotas should not affect existing production decisions or existing investment at home and abroad. Saputo will look at potential acquisitions in each market and the relative profitability of each. If milk production was growing in Canada that would have to be one of the considerations. Relaxing production constraints would allow Saputo to further rationalize its Canadian operations and thereby realize scale economies, possibly with green-field investments, leaving them with fewer resources (and possibly interest) in acquisitions of existing firms across all markets. ${ }^{17}$

Modelling liberalization of the Canadian dairy sector is problematic given the many possible avenues through which the liberalization can take place and the relatively few studies that examine the impact of expanding production. We follow Grant et al. (2014) and consider a growth scenario, with a liberalized dairy sector, where Canada's annual production grows from a current 9 billion liters to 23 billion liters. ${ }^{18}$ Holding fluid milk volumes constant, the existing volume of industrial milk is adjusted by compounded growth rates, over the sample period, to achieve a 23-billion-liter volume of total (fluid and industrial) milk. Given the new volumes of Canadian milk production, rates of change are then re-calculated for the total raw milk series and these series of rates of change are then introduced into the simulation.

Given new series for cash flows and Canadian milk production growth rates, the estimated logistic regression equation is used to predict new probabilities of acquisition for each quarter of the estimation period. The predicted quarterly probabilities are averaged over the time periods 1997-02, 2003-08, 2009-14, and 2015-18. Baseline average probabilities are compared with revised predicted probabilities that account for the removal of the Canadian supply management regime and are shown in Figure 4.

The impact of removing supply management on the average probability of acquisitions is illustrated (Figure 4) by the solid bars. In relative terms, the difference between the red and blue bars is declining since 2009. This is a period with significant foreign acquisitions so the relative Canadian share of total cash flows is declining (Figure 3) as is relative contribution of economic rents to these cash flows. When the rents are

\footnotetext{
${ }_{17}$ The relaxation of production quotas might have other implications for Saputo's investment strategies. For example, if reform was associated with increased imports and an increased potential for Canadian exports, then Saputo may be less interested in offshore acquisitions with access to major export destinations. However, if the reform maintained Canadian self sufficiency with market determined production then maintained interest in foreign acquisitions for export purposes would continue.

18 Grant et al. (2014) predicted that Canada's annual production would grow from 8 billion liters to 20 billion liters. These numbers have been updated to correspond to our end of sample of 9.2 billion liters of total raw milk production.
} 


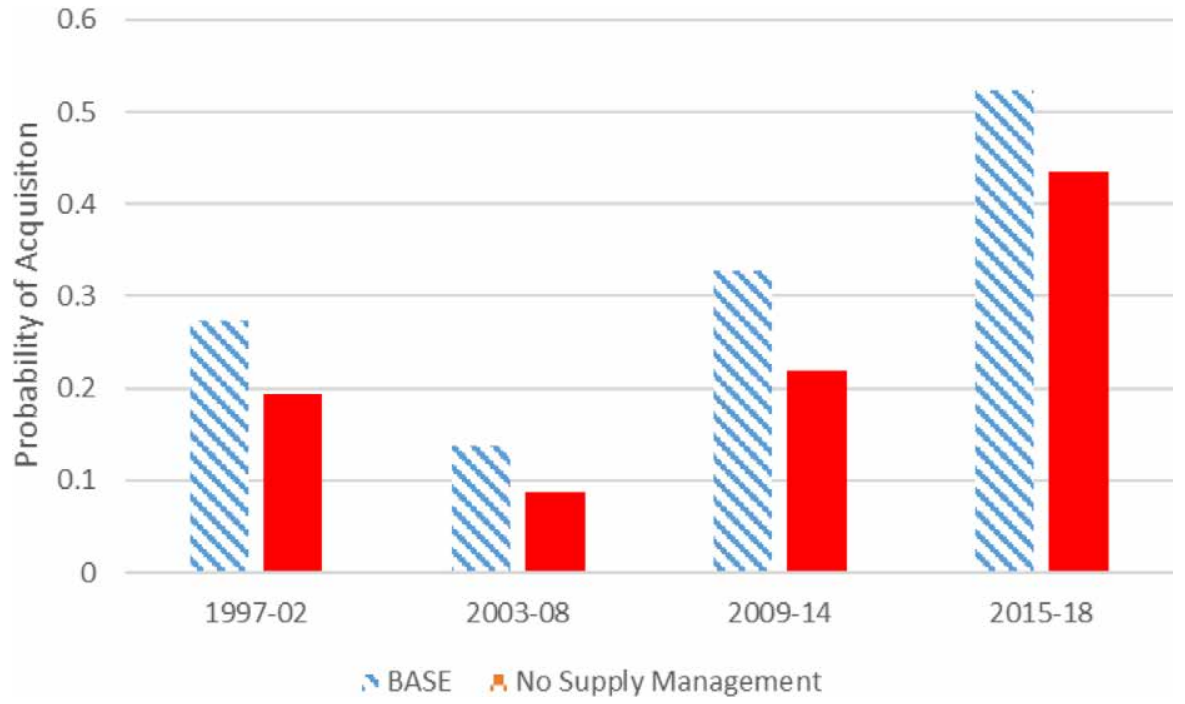

Figure 4. Predicted acquisition probabilities with and without supply management.

removed, the probability of acquisitions declines but in lower relative terms as compared to the previous 2003-09 period.

On average over the entire period removing supply management reduces the probability of acquisition by $7 \%$. Given the speculative nature of measuring this impact, some sensitivity analysis is in order. Adjusting the model coefficients for cash and quota growth to the lower end of the confidence interval for each $\left(\beta_{\text {cash }}=0.08\right.$ and $\beta_{\text {quota }}=-29$ ) reduces the probability of acquisition to $2 \%$. At the upper end of the confidence interval $\left(\beta_{\text {cash }}=0.37\right.$ and $\beta_{\text {quota }}=0.01$ ) the probability of an acquisition is $9 \%$. Despite the range of impacts, associated with the distributions of estimated coefficients, in every case removing the Canadian supply management regime reduces the probability of additional acquisitions regardless of the size of these coefficients. A significant and growing number of these acquisitions are international (Table 2), but as the company continues to grow outside of Canada, the effect of supply management on corporate decisions will be reduced as the Canadian share of the company's market continues to decline. ${ }^{19}$

Certainly, our method of accounting for the impact of supply management on cash reserves and Canadian milk production is open to criticism and at best is a crude approximation. However, the intent of the manuscript is to ask if the necessary conditions for Canadian dairy policy to positively impact Saputo's acquisitions are present.

\section{Conclusions}

Due to constricted input supply quotas, high raw milk costs and restrictive market regulations Canadian dairy processors are disadvantaged in accessing other export markets. Nonetheless, potential economic rents and a privileged position in a protected Canadian market also provide incentives for growth, much of which could be outside of Canada. ${ }^{20}$ Together these factors motivate and facilitate growth in foreign markets. Understanding how these factors contribute to Saputo's growth, not only helps better to appreciate the workings of the company, but also this understanding provides a window on the future of dairy processing in North America

This study presents an analysis of the factors that determine the decisions by Saputo to acquire competing processors. These decisions are measured as the probability of acquiring other firms. This probability is a

\footnotetext{
19 We included variables to account for acquisitions that were exclusively Canadian, but none were statistically significant.

${ }^{20}$ Saputo is not the only Canadian dairy processor to make foreign acquisitions. Agropur Coopérative has made significant acquisitions in the United States. However, as a cooperative much of this data is not publicly available.
} 
function of Saputo's financial position, exchange rates, and a measure of the restrictiveness of the Canadian dairy markets.

The impact of supply management is accounted for through cash flows and production quotas for raw milk. While the econometric model does not establish a causal relation between quota rents and their contribution to free cash flow, we consider a speculative exercise to account for the share of cash flows attributable to supply managed economic rents, and then determine how market liberalization might affect growth rates for raw milk production. This exercise allows us to consider a potential contribution that the current Canadian system may be making to the probability of Saputo making acquisitions of competitors.

The logit regression results confirm the potential for the Canadian regulatory regime to influence acquisition decisions. All of the financial control variables are of the expected sign and are significant (except debt to equity). Cash flows significantly increase the probability of acquisitions while increasing rates for the Canadian milk supply reduce the probability of acquisitions.

Although the results indicate that Saputo is more likely to make acquisitions because of supply management, the regime only explains part of the probability of acquisition. Saputo because of its own operational and financial strengths is able to grow and compete in foreign markets. In addition to these efficiencies, the supply management system in Canada contributes to the deep pockets that Saputo uses to finance foreign acquisitions. There remain possibilities for acquisitions outside Canada that Saputo may avail itself of, and that growth will likely be good for Saputo's shareholders given their success with previous acquisitions. The question of whether some of this growth could have provided employment and investment within Canada given a different system remains for further research although this study suggests such a possibility.

\section{References}

Adelaja, A., R. Nayga and Z. Faroog. 1999. Predicting mergers and acquisitions in the food industry. Agribusiness 15(1): 1-23.

Barchart. 2019. Financial statements - Saputo Inc (SAP.TO). Barchart, Chicago, IL, USA. Available at: https://www.barchart.com/stocks/quotes/SAP.TO/income-statement/annual

Business Development Bank of Canada. 2019. Canada tariff finder. Business Development Bank of Canada, Montreal, Canada.

Businesswire. 2020. Dean foods completes sale of assets to dairy farmers of America-completes sales to prairie farms dairy and producers dairy foods. Businesswire, San Francisco, CA, USA. Available at: https://www.businesswire.com/news/home/20200501005548/en/Dean-Foods-Completes-SaleAssets-Dairy-Farmers

Canadian Dairy Commission (CDC). 2019. Canadian milk supply management committee (CMSMC). CDC, Ottawa, ON, Canada. Available at: http://www.cdc-ccl.gc.ca/CDC/index-eng.php?id=3808

Canadian International Trade Tribunal (CITT). 1992. An inquiry into the allocation of import quotas. Government of Canada, Ottawa, ON, Canada. Available at: http://publications.gc.ca/collections/ collection_2017/citt/F43-6-91-001-eng.pdf

Canning, K. 2018. Top 100 dairy companies. Dairy Foods Magazine. Available at: https://www.dairyfoods. com/2018-dairy-100

Carter, C. and P. Mérel. 2016. Hidden costs of supply management in a small market. Canadian Journal of Agricultural Economics 49(2): 555-588.

Dairy Farmers of Ontario. 2006. Plant supply quota policy. Available at: https://www.milk.org/Corporate/ pdf/Processors-PSQPolicy.pdf

Federal Reserve Economic Data (FRED). 2019. Canada / U.S. foreign exchange rate. US Federal Reserve Bank of St Louis, MO, USA. Available at: https://fred.stlouisfed.org/series/DEXCAUS

Gitman, L. and C. Zutter. 2015. Principles of managerial finance, $7^{\text {th }}$ edition. Pearson, Boston, MA, USA. 
Global Affairs Canada. 2019. 2019 - CETA cheese quota holders list. Government of Canada, Ottawa, ON, Canada. Available at: https://www.international.gc.ca/controls-controles/prod/agri/dairy-laitiers/ CETA_cheese-19-fromage_AECG.aspx?lang=eng

Goldberg, W. 1983. Mergers: motives, modes and methods. Nichols Publishing Co., West Chester, PA, USA. Gopinath, M., D. Pick and U. Vasavada. 1999. The economics of foreign direct investment and trade with an application to the U.S. food processing industry. American Journal of Agricultural Economics 81(2): 442-452.

Gorton, G., M. Kahl and R. Rosen. 2009. Eat or be eaten: a theory of mergers and firm size. The Journal of Finance 63(3): 1291-1344. https://doi.org/10.1111/j.1540-6261.2009.01465.x

Grant, M., R. Barichello, M. Liew and V. Gill. 2014. Reforming dairy supply management: the case for growth. The Conference Board of Canada, Ottawa, ON, Canada. Available at: https://www.scribd. com/document/424655998/Conference-board-pdf-pdf

Guyonnet, B. 2016. Dairy sector consolidation: mergers \& acquisition, new investments and strategies. DFC Annual Dairy Policy Conference. February 3, 2016. Ottawa, ON, Canada

Hajderllari, L., K. Karantininis and L.G. Lawson. 2012. FDI as an export-platform: a gravity model for the danish agri-food industry. Technical report, Department of Food and Resource Economics, University of Copenhagen, Copenhagen, Denmark.

Hartford, J. 1999. Corporate cash reserves and acquisitions. The Journal of Finance 54(6): 1969-1997.

Honoré, B. and E. Kyriazidou. 2000. Panel data discrete choice models with lagged dependent variables. Econometrica 68(4): 839-874.

Kirby, J. 2019. The big cheese: how billionaire Lino Saputo Jr. built a global dairy empire and stood up to big milk. Report on Business Magazine, March 28, 2019.

Lash, E. 2019. Saputo continues to face private-label competition in a commodified environment. Morningstar Business Strategy and Outlook. Available at: http://analysisreport.morningstar.com/

Linter, J. 1971. Expectations, mergers and equilibrium in purely competitive securities markets. American Economic Review 61: 101-111.

Palepu, K. 1986. Predicting take-over targets: a methodological and empirical analysis. Journal of Accounting and Economics 8: 3-35.

Pouliot, S. and B. Larue. 2012. Import sensitive products and perverse tariff-rate quota liberalization. Canadian Journal of Economics 45(3): 903-924.

Rabobank. 2019. Global dairy top 20. RaboResearch Food \& Agribusiness, Utrecht, the Netherlands. Available at: https://research.rabobank.com/far/en/sectors/dairy/Dairy_top_20_2019.html

Richards, T. and M. Manfredo. 2003. Cooperative mergers and acquisitions: the role of capital constraints. Journal of Agricultural and Resource Economics 28(1): 152-168.

Saputo. 1998-2020. Annual information form. Available at: https://saputo.com/en/investors/shareholderreports $/ 2020$

Saputo, 2011. Annual report. Available at: https://www.saputo.com/en/investors/shareholder-reports/2011

Saputo. 2019. Saputo history. Available at: http://www.saputo.com/en/our-company/history-overview/2010-2017

Sparling, D. 2014. Saputo: project 4a: case studies on success traits. The Canadian Agri-food Policy Institute, Ottawa, ON, Canada. Available at: https:/capi-icpa.ca/wp-content/uploads/2014/02/Case-Studieson-Success-Traits-Saputo-2014.pdf

Standing Senate Committee on Agriculture and Forestry. 2018. Growing Canada's value-added food sector. Standing Senate Committee on Agriculture and Forestry, Ottawa, ON, Canada. Available at: https:// sencanada.ca/content/sen/committee/421/AGFO/reports/AGFO_SS-5_Report_Final_e.pdf

Statistics Canada. 2019. Milk production and utilization: milk sold off farms. Statistics Canada, Ottawa, ON, USA. https://doi.org/10.25318/3210011301-eng

United States Department of Agriculture - Foreign Agricultural Service (USDA-FAS). 2019. Dairy import license circular for 2019. Available at: https:/www.fas.usda.gov/sites/default/files/2020-03/dairy_ import_circular_jan_2020_final_numbers_for_all_2019.pdf

United States International Trade Commission (USITC). 2019. Official harmonized tariff schedule 2019. USITC, Washington, DC, USA. Available at: https://hts.usitc.gov/current 
Van Kooten, G.C. 2020. Reforming Canada's dairy sector: USMCA and the issue of compensation. Applied Economic Perspectives and Policy 42(3): 542-558. https://doi.org/10.1093/aepp/ppy038

Veeman, M. and Y. Peng. 1997. Dairy demand analysis. Department of Rural Economy, University of Alberta, Edmonton, AB, Canada.

Willis, A. 2019. For Saputo, chasing a deal with largest U.S. milk producer is a matter of risk and reward. The Globe and Mail: Report on Business, April 12, 2019. Available at: https://www.theglobeandmail. $\mathrm{com} /$ business/article-saputo-deepens-us-operations-with-possible-acquisitions-in-dairy/ 
